\title{
Microencapsulated Dopamine (DA)-Induced Restitution of Function in 6-OHDA-Denervated Rat Striatum in vivo: Comparison Between Two Microsphere Excipients
}

\author{
Amanda McRae ${ }^{1}$, Stephan Hjorth², David W. Mason ${ }^{3}$, Lynn Dillon ${ }^{3}$ and Thomas R. Tice \\ Departments of Histology ${ }^{1}$ and Pharmacology ${ }^{2}, P O B$ 33031, University of Göteborg, Göteborg, Sweden \\ 40033, and Controlled Release Division ${ }^{3}$, Southern Research Institute, Birmingham, AL 35255, USA
}

\section{SUMMARY}

Biodegradable controlled-release microsphere systems made with the biocompatible biodegradable polyester excipient poly [DL lactide-co-glycolide] constitute an exciting new technology for drug delivery to the central nervous system (CNS). The present study describes functional observations indicating that implantation of dopamine (DA) microspheres encapsulated within two different polymer excipients into denervated-striatal tissue assures a prolonged release of the transmitter in vivo. Moreover, in this regard, the results show that there were clear cut temporal differences in the effect of the two DA microsphere formulations compared in this study, probably reflecting variations in the actual composition (i.e., lactide to glycolide ratio) of the two copolymer excipients examined. This technology has considerable potential for basic research with possible clinical application.

Key words: Microencapsulated dopamine; poly [DL lactide-co-glycolide]; striatum; apomorphine; 6-hydroxydopamine.

Reprint address:

Amanda McRae

Department of Histology

POB 33031, University of Göteborg

Göteborg, Sweden 40033

\section{INTRODUCTION}

The main neurochemical characteristic of Parkinson's disease is a marked lesion of the nigro-striatal dopamine (DA) pathway. Current clinical management of Parkinson's disease relies strongly on substitution treatment with the DA precursor L-DOPA and/or direct DA agonists, administered via the parenteral route. In recent years several attempts have been made to reverse neurologically debilitating nigrostriatal DA deficiency by different alternative means of replacement therapy $/ 1 /$. Although some advances have been reported with neuronal and adrenal medullary tissue transplants, this approach has not yet proven simple and effective to compensate for the underlying DA neuronal loss in humans with Parkinson's disease /9-11/. Intracerebroventricular infusion is another method currently being tested in experimental Parkinsonism /4/ and in attempted replacement therapy of certain other neurodegenerative diseases $/ 6 \%$. Ideally, however, the delivery of substitution agents should be restricted specifically to the relevant damaged regions of the central nervous system (CNS).

Injectable drug delivery formulations - socalled microspheres - have recently been developed, in which drugs are microencapsulated within biocompatible and biodegradable copolymer excipients like poly [DL-lactide-coglycolide] $13 /$. These co-polymers are from the same class of material which has been used for nearly two decades in resorbable surgical sutures. The copolymer microsphere formulation 
protects drugs from degradation and allows release of the drug from its excipient at a controlled rate for prolonged periods of time (for weeks, or even months) $/ 3,20 /$. In view of its potential therapeutic usefulness, we have studied the microsphere methodology as a means of delivering DA to the rat central nervous system (CNS) in vivo. Specifically, our previous reports have indicated the feasibility of this approach and preliminary evidence suggested that intrastriatally implanted DA microspheres could, over long periods, counteract the postsynaptic DA receptor up-regulation resulting from unilateral 6-hydroxydopamine (6-OHDA) lesion of ascending dopaminergic neurons $/ 13,14 /$. Thus, these initial results support the concept that implantation of DA microspheres could provide an advantageous method for achieving prolonged release of functionally significant amounts of DA into striatal tissue in vivo to substitute for subnormal levels of the endogenous transmitter.

Another interesting advantage of the microspheres is that the duration of drug release can be modified by manipulating the "shell" constituent copolymer biodegradation kinetics, e.g., by changing the ratio of lactide to glycolide in the formulation $/ 20 /$. To this end, DA was microencapsulated in two copolymer excipients having different lactide to glycolide molar ratios. The object of this report is to compare these 2 different copolymer formulations. This is accomplished by comparing the duration of time that these intrastriatally implanted DA microspheres are able to reduce the extent of DA agonist-induced rotational behavior in unilaterally 6-OHDA-lesioned rats, used as a functional index of postsynaptic DA receptor denervation supersensitivity.

\section{MATERIALS AND METHODS}

\section{Animals, surgery and behavioral testing}

Twenty five male Sprague-Dawley rats (200$250 \mathrm{~g} ; \mathrm{AB}$ Laboratorietjänst, Sollentuna, Sweden) were unilaterally lesioned in the ascending median forebrain bundle (MFB) of monoamine neurons (coordinates A-P -4.3, $\mathrm{L}+1.4, \mathrm{D}-\mathrm{V}-8.7$ from bregma, midline, and top of skull, respectively) /16/. The neurotoxin used for the purpose was 6-hydroxydopamine $\mathrm{x} \mathrm{HCl}$ (6-OHDA; Sigma, St Louis, MO, USA), administered in a dose of $8 \mu \mathrm{g} / 4 \mu \mathrm{l}$ saline vehicle (containing $0.1 \%$ ascorbate). Two weeks after lesion, the rats were challenged with the classical DA agonist apomorphine $(0.1 \mathrm{mg} / \mathrm{kg}$ s.c.) and rotational responses were monitored in a computerized rotometer set-up /13/. Only rats in which the DA denervation has been successful ( $\geq 90 \%$ striatal DA depletion) will display strong contralateral rotation to apomorphine challenge in this model $/ 8,21 /$. Rats responding to apomorphine with less than 400 contralateral rotations per $60 \mathrm{~min}$ within the first two weeks of testing were eliminated from the study $(n=7)$. Testing of the remaining 18 positive responders was then continued on a weekly basis until a stable level of rotation was established (max $10 \%$ difference between three consecutive sessions). This criterion was typically met about 6 weeks after the initial testing session (data not shown).

\section{Polymers employed for encapsulation of DA}

DA was encapsulated in two types of copolymer excipient. One copolymer had a 50:50 molar ratio of lactide to glycolide (referred to as DA 50:50). The other copolymer had a 65:35 molar ratio of lactide to glycolide (DA 65:35). It was predicted that, because of its higher lactide content, the $65: 35$ copolymer will take longer to biodegrade than the 50:50 copolymer, thus potentially affording a longer duration of delivery of DA in vivo.

\section{Implantation of DA microspheres}

Once rats reached a stable rotational baseline level to DA agonist challenge (cf. above) they were stereotaxically injected under light ether anesthesia with a suspension of DA microspheres (prepared immediately prior to injection). DA 50:50 microspheres ( $\mathrm{n}=5 ; 15 \mathrm{mg}$ microspheres $/ 50 \mu$ l saline) or DA $65: 35$ microspheres ( $\mathrm{n}=9 ; 30 \mathrm{mg}$ microspheres/50 $\mu \mathrm{l})$ were implanted into two sites ( $3 \mu \mathrm{l}$-deposits, 2 levels/site) in the mediocentral striatum (A-P + 0.7, L 2.3, D-V -4.5 and -5.5; A-P + 0.2, L 2.3, D$\mathrm{V}-4.5$ and -.5 .5 ) /16/. DA 50:50 is predicted to 
biodegrade twice as fast as DA $65: 35 / 13 /$. To ensure that similar amounts of DA would be released per unit time the quantity of DA 65:35 microspheres was therefore twice that of the DA 50:50 microspheres. A separate group of control rats $(n=4)$ received corresponding injections of empty microspheres (50:50 polymer formulation; $30 \mathrm{mg}$ microspheres $/ 50 \mu 1$ saline).

The injections were performed with a 10 microliter glass capillary tube (calibrated at 3 microliter intervals) connected to a standard Hamilton syringe $(50 \mu \mathrm{l})$ via polyethylene tubing. The entire duration of injection was $3 \mathrm{~min} / \mathrm{site}$. Upon completion of the second infusion, the injection cannula was left in situ for an additional 60 seconds before being slowly retracted. The skin wound was closed with surgical clips and the animals allowed to recover from anesthesia (about 30-45 minutes thereafter). They were placed into the rotometers and their behavior recorded for the subsequent 2-3 hours. Starting one week after implantation of the DA microspheres, the rats were repeatedly tested for DA agonist-induced rotation on a weekly basis for 6-8 weeks.

\section{Histology}

At the termination of the 6-8 week schedule the rats were perfused with $5 \%$ glutaraldehyde and a series of consecutive sections $(10 \mu \mathrm{m})$ of the striatum was incubated with anti-DA antiserum $/ 7,12 /$. The immunocytochemistry was performed with the standard avidin-biotin complex method, thus allowing visualization of tissue DA immunoreactivity.

\section{Statistics}

The data are presented as the total number of apomorphine-induced contralateral rotations summed over 60 minutes, means \pm SEM. Statistical comparisons between postimplantation responses and pre-implantation baseline values ( $=$ obtained in the last apomorphine test session before implantation) were made employing Student's paired t-test. The results were expressed as the mean and standard error of the mean (SEM). Probability levels of $5 \%$ or less were considered statistically significant.
RESULTS

Acute rotational response to DA microsphere implantation

The 18 rats selected for microsphere implantation experiments had responded with the typical "two-peak" contralateral rotation pattern when initially challenged with apomorphine $(0.1 \mathrm{mg} / \mathrm{kg}$ s.c. $)$, a reliable indicator of $>90 \%$ DA lesion success $/ 8,21 /$. As previously reported /14/, upon recovery from ether anesthesia $(=30-45 \mathrm{~min}$ after intrastriatal implantation of DA microspheres) rats exhibited immediate contralateral rotational behavior with an amplitude comparable to that of apomorphine $(0.1 \mathrm{mg} / \mathrm{kg} \mathrm{s.c.})$ but with longer duration. Rats receiving DA 65:35 microspheres displayed a somewhat more protracted response to the microsphere implantation but had a peak rotation amplitude similar to the DA 50:50 microsphere group /14/. Animals implanted with empty microspheres did not display rotationa! behavior.

Rotational responses to apomorphine in DA microsphere-implanted rats

\section{DA 50:50 implants}

The total number of pre-implantation contralateral rotations for this group of rats was $553 \pm$ $58(\mathrm{n}=5)$. When compared to this value, the central striatal DA 50:50 microsphere implants resulted in a reduction to $397 \pm 19$, a $29 \%$ decrease in the total number of apomorphineinduced contralateral rotations 4 weeks postimplantation. During the subsequent two weeks the response to apomorphine challenge slowly approached the pre-microsphere baseline (Fig. 1). At 6 weeks there was a reduction to $497 \pm 48$, representing a non-significant $11 \%$ decrease in the total number of apomorphine-induced contralateral rotations.

\section{DA 65:35 implants}

The total number of pre-implantation contralateral rotations for this group of rats was $506 \pm$ $26(n=9)$. The DA 65:35 microspheres resulted in a reduction to $319 \pm 43$, representing a $37 \%$ 
decrease in the total number of apomorphineinduced contralateral rotations two weeks postimplantation. From then on and up to 8 weeks following implantation there was an average reduction to $375 \pm 50$, corresponding to a $26 \%$ decrease in the total number of apomorphineinduced contralateral rotations (Fig. 2). Since, as indicated above, the DA 65:35 polymer excipient was predicted to outlast the DA 50:50, it is interesting to note that the reduction in the number of apomorphine rotations from week 3 through week 8 remained rather stable with the former formulation whereas the apomorphine response in the DA 50:50 group was no longer significantly suppressed after week 5 .

\section{Sham implants}

During the 6 week testing period postimplantation, rats that received empty microspheres did not display any significant change in the number of apomorphine-induced contralateral rotations when compared to the pre-implantation baseline (Fig. 3).

\section{Immunocytochemistry}

Micrographs of DA 50:50 are not presented in this report. However, previously we demonstrated that DA was present in DA 50:50 microspheres 3 weeks after implantation /14/. Our immunocytochemical observation of these microspheres 6 weeks after implantation revealed that the majority of the microspheres had biodegraded or were in the process of doing so. There were, however, sparse traces of DA immunoreactivity in some microspheres that had not fully biodegraded. In no case was the immunocytochemical reaction comparable to that of DA 65:35. In the DA 65:35 implant group, however, there were still microspheres containing respectable amounts of DA at 8 weeks (Fig. 4A-B). Examination of the micrographs in this latter group also reveals microspheres in the process of biodegrading at 8 weeks post-implantation (Fig. 4B). No DA immunoreactivity was present in the microspheres or in the striatal tissue of the "sham"

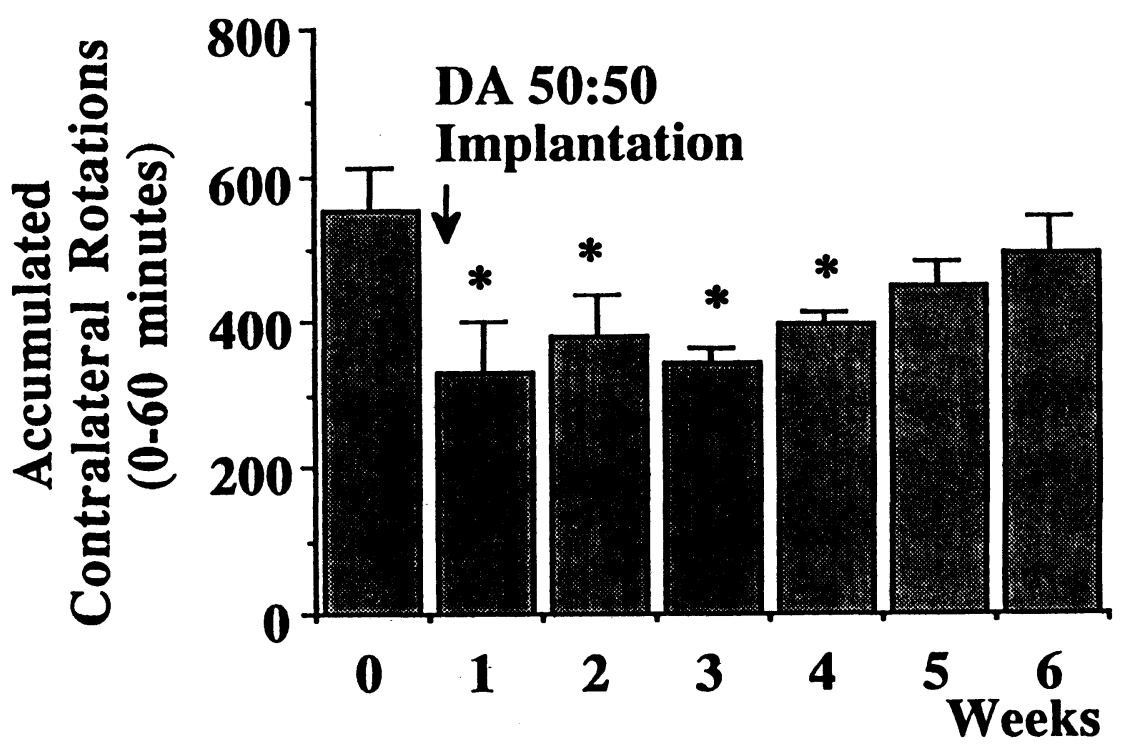

Fig. 1: Total number of apomorphine-induced contralateral rotations in 6-OHDA-treated rats before and for 6 consecutive weeks following implantation of DA 50:50 microspheres. Bars represent the mean \pm SEM $(n=$ 5). The pre-implantation baseline value $C=$ obtained in the last apomorphine test session before implantation) was $553 \pm 58$. This value is shown at time 0 . The number of apomorphine-induced contralateral rotations post implantation were as follows: 1 week $331 \pm 73,2$ weeks $382 \pm 59,3$ weeks $345 \pm 20,4$ weeks $397 \pm 19,5$ weeks $453 \pm 30$ and 6 weeks $497 \pm 48$. Abscissa, time in weeks; ordinate, accumulated contralateral rotations recorded for 60 minutes. Statistics: paired t-test *p $<0.05$ compared to the pre-implantation baseline value. 


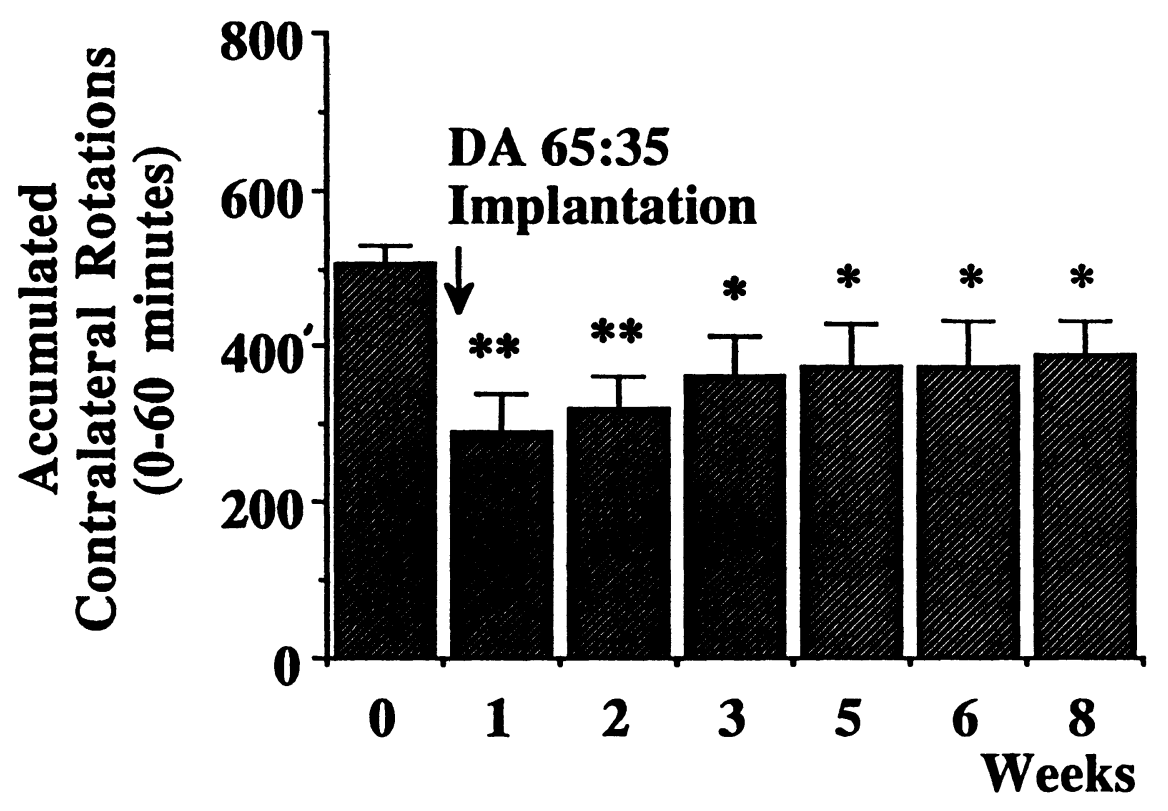

Fig. 2: Total number of apomorphine-induced contralateral rotations in 6-OHDA-treated rats before and for 8 consecutive weeks following implantation of DA 65:35 microspheres. Bars represent the mean \pm SEM $(n=$ 9). The pre-implantation baseline value $C=$ obtained in the last apomorphine test session before implantation) was $506 \pm 26$. This value is shown at time 0 . The number of apomorphine-induced contralateral rotations post implantation were as follows: 1 week $290 \pm 51,2$ weeks $319 \pm 43,3$ weeks $364 \pm 51,5$ weeks $376 \pm 52,6$ weeks, $375 \pm 56$, and 8 weeks $391 \pm 42$. Abscissa, time in weeks; ordinate, accumulated contralateral rotations recorded for 60 minutes. Statistics: paired t-test *p $<0.05$, * 0.001 compared to the pre-implantation baseline value.

microsphere-implanted rats, thus equally supporting the specificity of the DA antibody reaction and confirming the efficiency of the 6OHDA lesion. Judging from routine microscopic examination of the injection areas in DA 50:50, DA 65:35 and "sham"-treated animals, the implantation of microspheres into the striatum did not appear to induce inflammatory reactions nor to result in damage to the surrounding tissue (cf. Fig. 4A-C). These observations suggest the biocompatibility of the microencapsulated DA within CNS tissue.

\section{DISCUSSION}

The present investigation demonstrates that implantation of microencapsulated DA in the central striatum can counteract, over substantial periods of time, apomorphine-induced rotational behavior in rats with chronic unilateral 6-OHDA lesions of ascending (nigrostriatal) dopaminergic neurons, thereby confirming our previous preliminary findings $/ 14 /$. The attenuated responsiveness to DA agonist challenge in this experimental model is likely to be explained by a down-regulation of denervation-sensitized striatal postsynaptic DA receptors, following implantation of the in vivo DA-releasing microspheres $/ 13,14 /$. Moreover, in this regard, the results show that there were clear cut temporal differences in the effect of the two DA microsphere formulations compared in this study, reflecting variations in the actual composition (i.e., lactide to glycolide ratio) of the two copolymer excipients examined.

The DA 50:50 and DA 65:35 excipients were predicted to biodegrade at different time intervals, while simultaneously unloading functionally significant amounts of the polymerencapsulated DA. Our data support the validity of these predictions under in vivo conditions. 


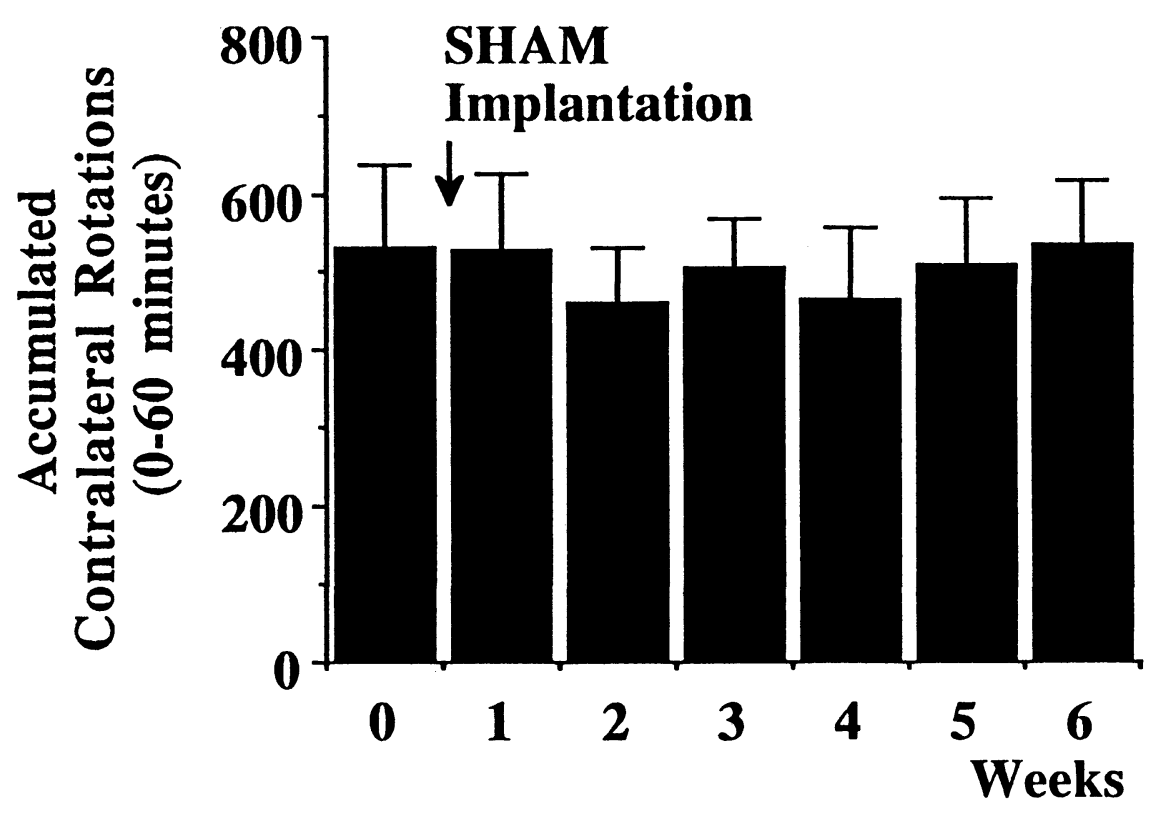

Fig. 3: The number of apomorphine-induced contralateral rotations in 6-OHDA-treated rats before and for 6 consecutive weeks following implantation of empty microspheres. Bars represent the mean $\pm \operatorname{SEM}(n=4)$. The pre-implantation baseline value (= obtained in the last apomorphine test session before implantation) was $532 \pm 108$. This value is shown at time 0 . The number of apomorphine-induced contralateral rotations post implantation were as follows: 1 week $529 \pm 97,2$ weeks $460 \pm 73,3$ weeks $506 \pm 66,4$ weeks $465 \pm$ 92, 5 weeks $510 \pm 86$ and 6 weeks $536 \pm 83$. Abscissa, time in weeks; ordinate, accumulated contralateral rotations recorded for 60 minutes. There was no statistical difference in the number of contralateral rotations post-implantation compared to the pre-implantation baseline value.

Immediately after implantation into the central striatum, both the DA 50:50 and the DA 65:35 microsphere mixtures elicited strong contralateral rotation, considered to be mediated by postsynaptic DA receptor stimulation. However, this behavioral response vanished over a period of about 3-4 h, tentatively due to rapid receptor desensitization $/ 13,14 /$. In the subsequent weekly test sessions the DA 50:50 microsphere group displayed a significantly reduced total number of apomorphine-induced contralateral rotations up to and including the 4th testing week postimplantation. However, in the DA 65:35 experiment the apomorphine response was reduced for at least 8 weeks. Even at this time the response to the DA agonist challenge was significantly lower than the pre-implantation baseline, suggesting that there was still enough DA remaining to maintain a reduction of the 6OHDA-induced denervation supersensitivity. This interpretation is further supported by the immunocytochemical analysis, revealing the persistence of microspheres with intact or nearintact DA contents also at 8 weeks after implantation (cf. Fig. 4A-B). It is also interesting to note in this context that the time-course and extent of reduction in denervation supersensitivity produced by implantation of DA 65:35 microspheres is comparable with that reported after striatal grafting of adrenal medullary chromaffin tissue /19/.

Our results support the idea that the altered duration of in vivo release of encapsulated drug from resorbable polymer excipients is a function of the actual copolymer composition. There is convincing evidence from in vitro experiments that the rate of drug release from microspheres is very sensitive to variations in the excipient constituents $/ 2,20 /$. Interestingly, this seems to apply also in vivo, the major difference being that in this case the time scale for microsphere biodegradation is now weeks/months rather than minutes/hours $/ 20 \%$. In the present study, the implanted 65:35 DA microspheres resulted in a 

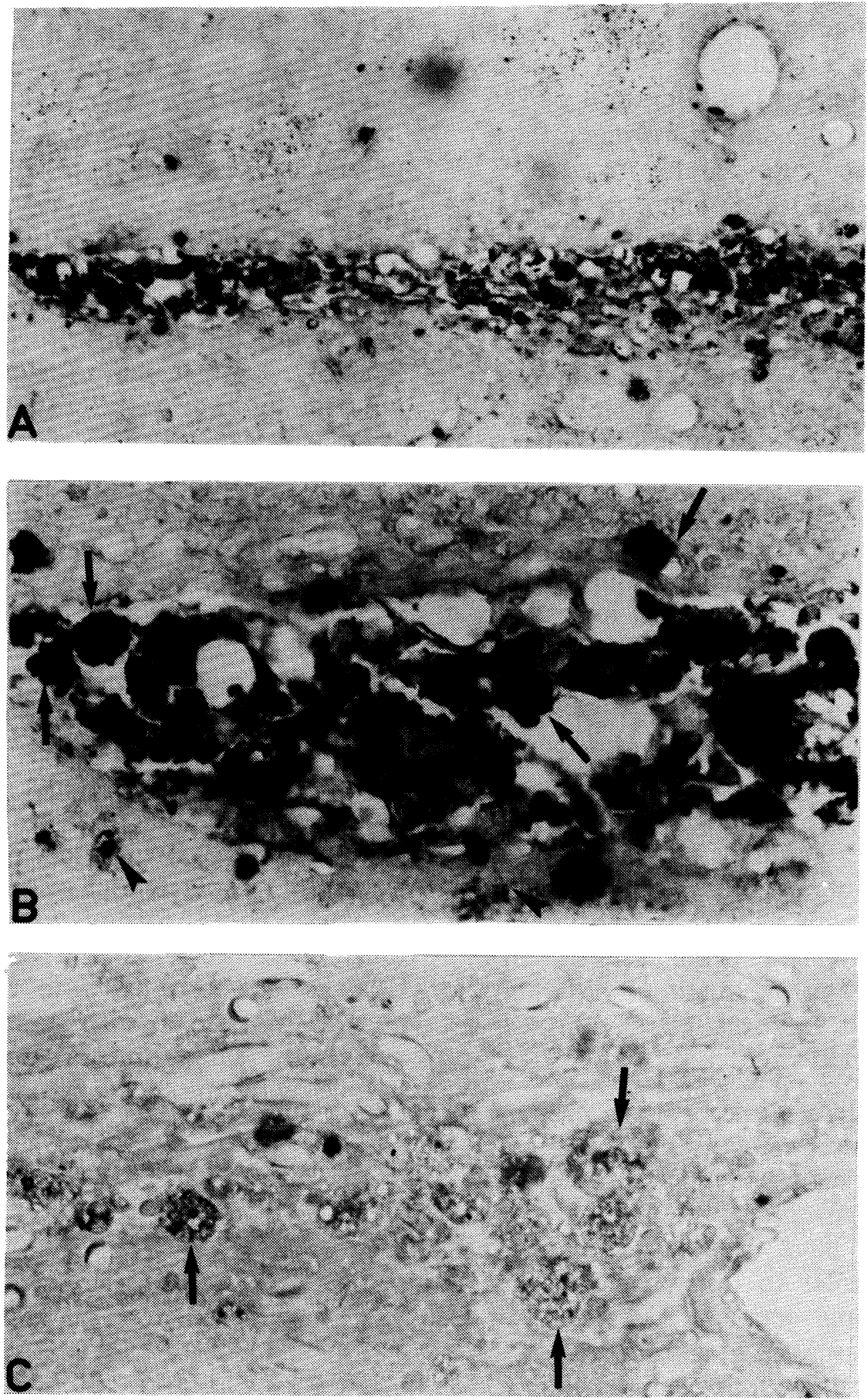

Fig. 4: Photomicrographs of frontal cryostat sections $(10 \mu \mathrm{m})$ of the denervated striatum after implantation of DA 65:35 $(A, B)$ or empty $(C)$ microspheres. All the sections were incubated with anti-DA antiserum $(1 / 500)$. The sections were processed for immunocytochemistry using the standard avidin-biotin-peroxidase complex method.

A DA 65:35 microcapules 8 weeks following implantation. Notice that the tissue on either side of the injection tract is intact. DA microspheres depicted by the immunocytochemical reaction are still within the striatum. $\times 160$.

B This photomicrograph is a higher magnification of A. A number of immunoreactive DA microspheres can be observed (arrows). There are some microcapules in the process of degrading (arrow heads). $\times 640$.

C Empty microspheres (arrows) 6 weeks after implantation. Notice that these microspheres are totally devoid of immunoreactivity. $\times 640$. 
rather constant reduction in the apomorphine response from week 3 through week 8 . Thus, it appears that even though the liberation of DA from these polymers relies on hydrolytic surface erosion in vivo, the rate of this process is dependent on the actual excipient composition so as to allow reasonable control of the release in the manufacturing step by, e.g., altering the lactide to glycolide ratio in the copolymer. This concept is also supported by the results with the 50:50 DA microspheres. Importantly, the present data equally support the biocompatibility of the microsphere formulations. It might be suggested that biodegradation through hydrolysis of the excipients used would be harmful to the brain tissue. If so, it could be expected that the striatal tissue would be damaged during the process and thus the rats would no longer be able to respond to apomorphine after termination of the biodegradation period. Our results clearly demonstrate that this is not the case. First, the immunocytochemical study revealed that introduction of the microspheres produced minimal (if any) tissue damage (cf. Fig. 4). Secondly, the DA 50:50 animals returned to preimplantation baseline values, and thirdly, animals implanted with "sham" microspheres (without DA, but of the same shell composition) did not display any reduction in their apomorphine-induced rotational behavior over the entire 6-week period studied.

The present copolymer microsphere preparations appear to compare favorably with other reported polymeric excipient devices used in studies aiming for sustained release of DA. Other researchers have recently reported functional results similar to ours, using single, mm-thick ethylene-vinyl acetate (EV Ac) DAcontaining copolymer matrix rods or discs $15,22 /$. As compared to the microsphere preparations, these latter polymer designs inevitably cause much more mechanical tissue damage by virtue of their size when implanted and removed /22/; indeed, aspiration of parts of the overlying neocortex was required in order to put the discshaped DA-entrapping polymer in position for release into the striatum $/ 5 /$. Moreover, the EV Ac devices are non-resorbable and while, in one of the studies, only restricted gliosis was reported 15/, the chronic biocompatibility also remains to be established. Although the microspheres used in our studies cannot be removed once implanted, they cause minimal tissue damage and no additional manipulation of the experimental animal is necessary to get the DA within reach of the striatal tissue.

As referred to above, the DA 50:50 microsphere implants into the central portion of the striatum resulted in a clear-cut, $\geq 4$-week long, blunting of the response to apomorphine challenge. In contrast, in a previous study, we found no attenuation in the rotational response to apomorphine 3 - 40 days after lateral striatal DA 50:50 microsphere implants /14/. The present results therefore represent another addition to the growing list of examples of functional heterogeneity of the striatum $/ 15,17,18,23 /$.

Injectable microsphere formulations have earlier been demonstrated as a feasible means of delivering drugs at intended sites of action, for prolonged periods of time, at required rates and in proper therapeutic doses, to targets outside the blood brain barrier $/ 20 /$. The present results indicate that DA microsphere preparations have the potential of being employed as a source of transmitter replacement also within brain tissue in vivo. These formulations allow sustained diffusion of the microencapsulated DA into the CNS at a controlled rate for predetermined periods of time, assure functional significance and at the same time appear to remain compatible with the host tissue. This new "slowrelease", target-directed approach provides not only a useful tool in basic neuroscience but conceivably, after completing similar experiments in non-human primates, it may also be employed in the clinical management of neurodegenerative illness such as Parkinson's disease.

\section{ACKNOWLEDGEMENTS}

Prof. Annica Dahlström (A.D.) is thanked for providing the necessary facilities for the immunocytochemical study; we also appreciate her constant interest in this work. The financial support from Söderbergs, Goljes, Stohnes and Krapperups Foundations, "Riksbanken Jubileumsfond" and A. and M. Axson Johnson Stifelser 
to A.D., The Medical Faculty of the University of Göteborg and from the Swedish MRC (no. 7486 to S.H. and nos. 2207 and 8168 to A.D.) is gratefully acknowledged. We thank Mr. George McFarlane and Ms. Anne Kling-Pedersen for skillful technical assistance.

\section{REFERENCES}

1. Björklund $A$, Lindvall $O$, Isacson $O$, Brundin $P$, Wictorin K, Strecker RE, Clarke DJ, Dunnett SB. Mechanisms of action of intracerebral neural implants: Studies on nigral and striatal grafts to the lesioned striatum. TINS 1987; 10: 509-516.

2. Bodmeier $\mathrm{R}, \mathrm{Oh} \mathrm{KH}$, Chen $\mathrm{H}$. The effect of the addition of low molecular weight poly(dl-lactide) on drug release from biodegradable poly (dl-lactide) drug delivery systems. Int J Pharmaceut 1989; 51: 1-8.

3. Cowsar DR, Tice TR, Gilley RM, English JP. Poly (lactide-co-glycolide) microspheres for controlled release of steroids. In: Methods in Enzymology, vol. 112. New York: Academic Press, 1985; 101-116.

4. De Yebenes JG, Fahn S, Jackson-Lewis V, Mena MA. The effect of intracerebroventricular infusion of $(t)$ 4-propyl-9-hydroxynaphthoxazine (PHNO) through a totally implanted drug delivery system in rats with dopamine deficiency. Movement Disorders 1987; 2: 291-299.

5. During MJ, Freese A, Sabel WM, Deutch A, Roth $\mathrm{RH}$, Langer $\mathrm{R}$. Controlled release of dopamine from a polymeric brain implant: in vivo characterization. Ann Neurol 1989; 25: 351-356.

6. Gauthier S, Leblanc R, Quirion R, Carlsson G, Beaulieu M, Bouchard R, Dastoor D, Ervin F, Gauthier L, Gauvin M, Henry J, Palmour R, Robitaille Y. Transmitter-replacement therapy in Alzheimer's disease using intracerebroventricular infusions of receptor agonists. Can J Neurol Sci 1986; 13: 394-402.

7. Geffard M, Patel S, Dulluc J, Rock A. Specific detection of noradrenaline in rat brain by using antibodies. Brain Res 1986; 363: 395-400.

8. Herrera-Marschitz M, Strömberg I, Olsson D, Ungerstedt U, Olson L. Adrenal medullary implants in the dopamine-denervated rat striatum. II. Acute behavior as a function of graft amount and location and its modulation by neuroleptics. Brain Res 1984; 297: 53-61.

9. Lindvall $O$, Rehncrona $S$, Brundin $P$ et al. Human fetal dopamine neurons grafted into the striatum in two patients with severe Parkinson's disease. A detailed account of methodology and a 6 month follow up. Arch Neurol 1989; 46: 615-631.

10. Lindvall $\mathrm{O}$, Brundin $\mathrm{P}$, Widner $\mathrm{H}$ et al. Grafts of fetal dopamine neurons survive and improve motor function in Parkinson's disease. Science 1989; 247: 574-577.

11. Madrazo I, Drucker-Colin R, Diaz V, Martinez-Mata J, Torres C, Becerril JJ. Open micro-surgical autograft of adrenal medulla to the right caudate nucleus in 2 patients with intractable Parkinson's disease. New Engl J Med 1987; 316: 831-834.

12. McRae-Degueurce A, Rosengren I, Haglid $\mathrm{K}$, Augustsson I, Dahlström A. Dopaminergic terminals in the rat locus coeruleus: An immunocytochemical investigation. Acta Physiol Scand 1988; 133: 583-585.

13. McRae-Degueurce A, Hjorth S, Dillon L, Mason D, Tice $T$. Implantable microencapsulated dopamine (DA): A new approach for slow-release DA delivery into brain tissue. Neurosci Lett 1988; 92: 303-309.

14. McRae A, Hjorth S, Mason D, Dillon L, Tice T. Implantable microencapsulated dopamine (DA): Prolonged functional release of $\mathrm{DA}$ in denervated striatal tissue. J Neural Transm, 1990; Suppl 29: 207215.

15. Orr WB, Stricker EM, Zigmond MJ, Berger TW. Effects of dopamine depletion on the spontaneous activity of type I striatal neurons: Relation to local dopamine concentration and motor behavior. Synapse 1987; 1: 461-469.

16. Paxinos G, Watson C. The Rat Brain in Stereotaxic Coordinates. New York: Academic Press, 1982.

17. Pisa $M$, Schrantz J. Dissociable roles of the rat's striatum conform to a somatotopic model. Behavioral Neurosci 1988; 102: 429-440.

18. Savasta M, Dubois A, Feuerstein C, Manier M, Scatton B. Denervation supersensitivity of striatal D2 dopamine receptors is restricted to the ventro- and dorsolateral regions of the striatum. Neurosci Lett 1987; 74: 180-186.

19. Strömberg I, Herrera-Marschitz M, Hultgren L, Ungerstedt U, Olson L. Adrenal medullary implants in the dopamine-denervated rat striatum. I. Acute catecholamine levels in grafts and host caudate as determined by HPLC-electrochemistry and fluorescence histochemical image analysis. Brain Res 1984; 297: 41-51.

20. Tice TR, Cowsar DR. Biodegradable controlledrelease parenteral systems. Pharmaceut Technol 1984 (November); 26-35.

21. Ungerstedt U. Postsynaptic supersensitivity after 6hydroxydopamine induced degeneration of the nigrostriatal dopamine system. Acta Physiol Scand 1971; Suppl 367: 69-93.

22. Winn SR, Wahlberg L, Tesco PA, Aebischer P. An encapsulated dopamine-releasing polymer alleviates experimental Parkinsonism in rats. Exp Neurol 1989; 105: 244-250.

23. Yamamoto BK, Pehek EA. A neurochemical heterogeneity of the rat striatum as measured by in vivo electrochemistry and microdialysis. Brain Res 1990; 506: 236-242. 

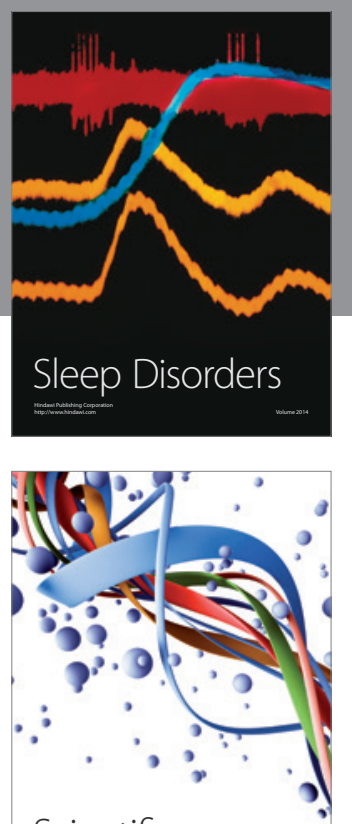

Scientifica
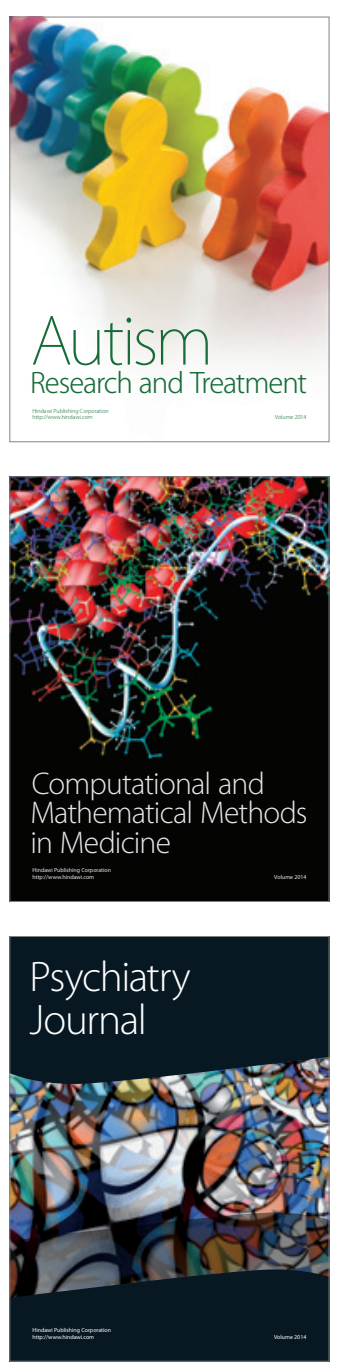
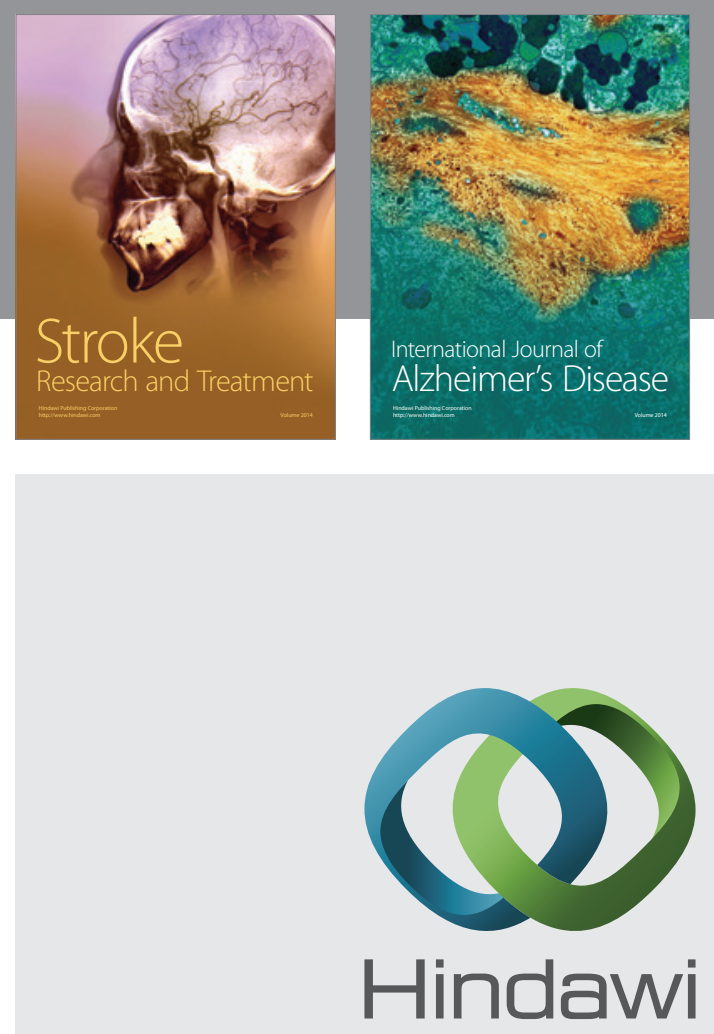

Submit your manuscripts at

http://www.hindawi.com
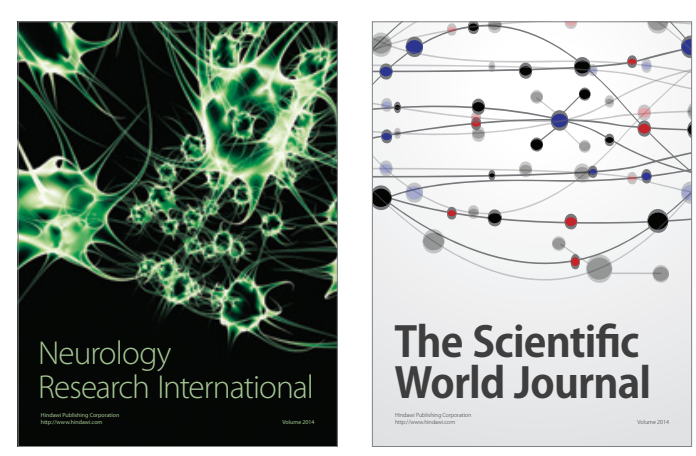

The Scientific World Journal

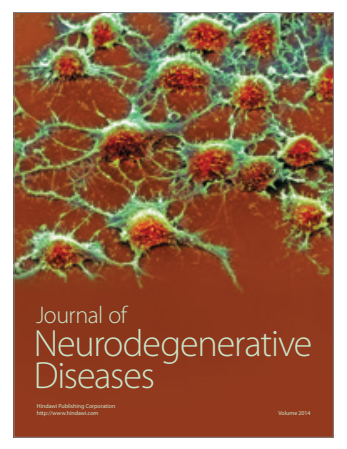

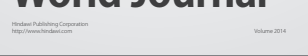

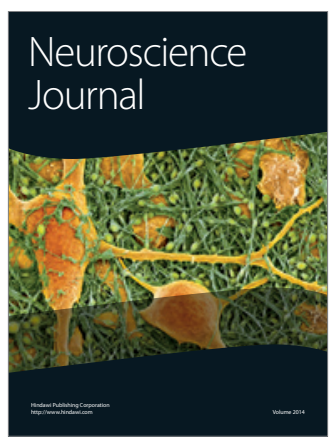

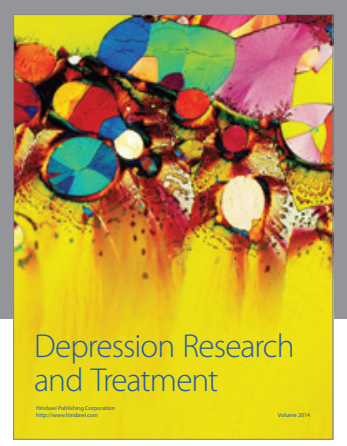
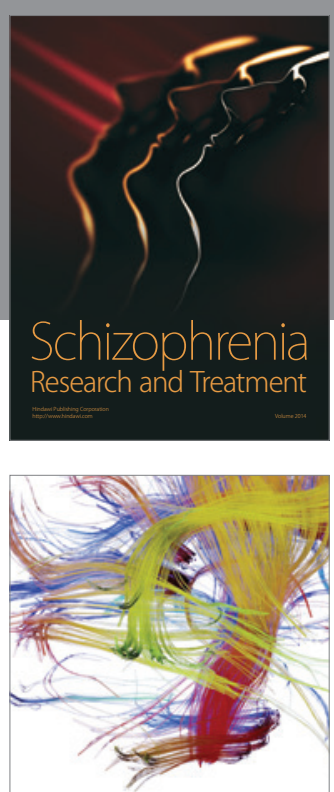

Brain Science

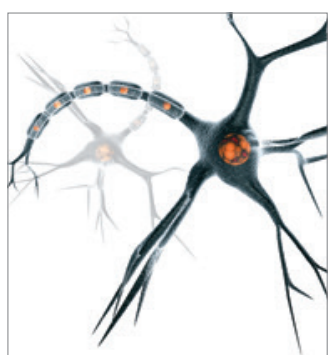

Neural Plasticity
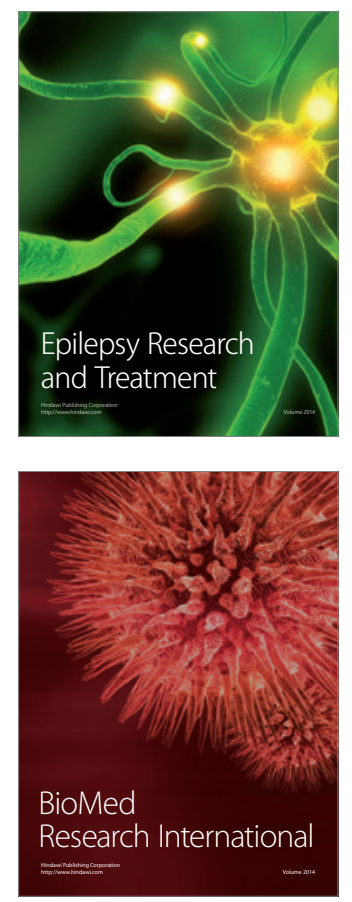

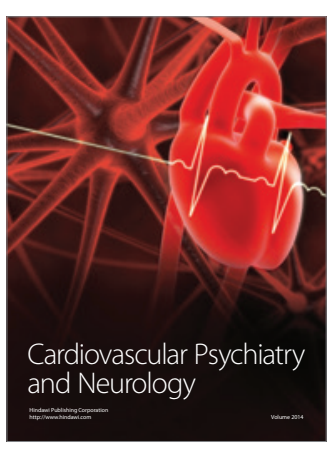

Parkinson's

Disease
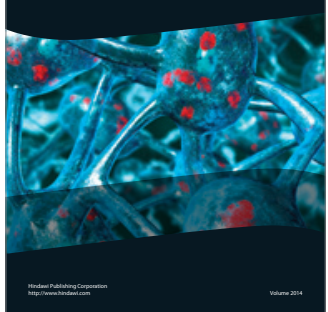